\title{
A solitary pulmonary nodule caused by Mycobacterium avium with pleural effusion and pleuritis after transbronchial biopsy: a case report
}

\author{
Shigenari Nukaga ${ }^{1 *}$, , Hiroaki Murakami ${ }^{1}$, Kazuma Yagi ${ }^{1}$, Ryosuke Satomi ${ }^{1}$, Takahiko Oyama ${ }^{1}$, \\ Arafumi Maeshima ${ }^{2}$ and Yoshitaka Oyamada ${ }^{1}$
}

\begin{abstract}
Background: Pleural effusion and pleuritis are uncommon manifestations of Mycobacterium avium complex pulmonary disease. Pleuritis caused by Mycobacterium avium complex pulmonary disease presenting as a solitary pulmonary nodule is extremely rare. The pathogenesis of Mycobacterium avium complex pleuritis has not been elucidated. However, it has been suggested that secondary spontaneous pneumothorax from Mycobacterium avium complex pulmonary disease is one of the causes of Mycobacterium avium complex pleuritis.
\end{abstract}

Case presentation: A 67-year-old Japanese woman who presented with a solitary pulmonary nodule developed a transient pneumothorax after transbronchial biopsy. A definitive diagnosis of solitary pulmonary nodule could not be made on bronchoscopy, so video-assisted thoracoscopic surgery was performed 1 month after bronchoscopy. On the day of hospitalization for the procedure, a left-sided pleural effusion appeared on a chest radiograph. Thickening of the parietal and visceral pleura and numerous scattered white small granules were seen on thoracoscopy. Histologic examination of the resected left lower lobe and a biopsy of the parietal pleura showed Mycobacterium avium complex solitary pulmonary nodule and Mycobacterium avium complex pleuritis.

Conclusion: latrogenic pneumothorax can be a cause of pleuritis in a patient with Mycobacterium avium complex pulmonary disease. Clinicians should watch for the appearance of secondary pleuritis after transbronchial biopsy even in a patient with localized disease such as Mycobacterium avium complex solitary pulmonary nodule.

Keywords: Mycobacterium avium complex pulmonary disease, Solitary pulmonary nodule, Pleuritis, Pneumothorax

\section{Background}

The incidence of pulmonary disease caused by nontuberculous mycobacteria (NTM) has been increasing globally $[1,2]$. Mycobacterium avium complex (MAC), including Mycobacterium avium and Mycobacterium intracellulare, is the most common cause of NTM pulmonary

\footnotetext{
*Correspondence: shigenarism@hotmail.co.jp

${ }^{1}$ Respiratory Medicine, National Hospital Organization Tokyo Medical Center, 2-5-1, Higashigaoka, Meguro, Tokyo 152-8902, Japan

Full list of author information is available at the end of the article
}

disease (NTM-PD) [3, 4]. The radiologic findings of MAC pulmonary disease (MAC-PD) are commonly classified as fibrocavitary or nodular bronchiectatic [5]. However, some cases of MAC-PD present as a solitary pulmonary nodule (MAC-SPN) [6, 7]. Although MAC-PD generally shows chronic and indolent progression [7], pleuritis may occur as a rare complication [8-12]. The pathogenesis of MAC pleuritis has not been elucidated. However, it has been suggested that pneumothorax is one of the causes of MAC pleuritis [8]. In this article, we describe a patient 
with MAC-SPN who developed pleuritis after pneumothorax attributable to transbronchial biopsy.

\section{Case presentation}

A 67-year-old Japanese woman was referred to our hospital for investigation of an abnormal shadow in the left lower lung field on chest radiography (Fig. 1a). She was asymptomatic and had no significant past medical history. Chest computed tomography (CT) showed a solitary nodule measuring $22 \mathrm{~mm}$ in diameter in the periphery of the left lower lobe (Fig. 2). The laboratory findings, including tumor markers, an interferongamma release assay (T-SPOT.TB, Oxford, Immunotec, Abingdon, UK), $\beta$-D-glucan, and serum cryptococcal antigen were negative. There were no findings suggestive of immunodeficiency or diabetes mellitus. A bronchoscopy with transbronchial biopsy and bronchial lavage were performed to diagnose the solitary pulmonary nodule. Adequate specimens were collected; however, a chest radiograph obtained immediately after a bronchoscopy showed a left-sided pneumothorax (Fig. 1b). The pneumothorax was small and asymptomatic, so the patient was observed without intervention and recovered within a few days. Although Mycobacterium avium was cultured from bronchial lavage fluid, histologic examination of the biopsy specimens showed nonspecific chronic inflammation with atypical B-cell proliferation. We could not make a definitive diagnosis of the nodule, and malignancy was unable to be ruled out. To investigate the nodule further, surgical lung resection was planned. The patient was hospitalized for surgery 1 month after her bronchoscopy. Although she had no fever, cough, or shortness of breath, a chest

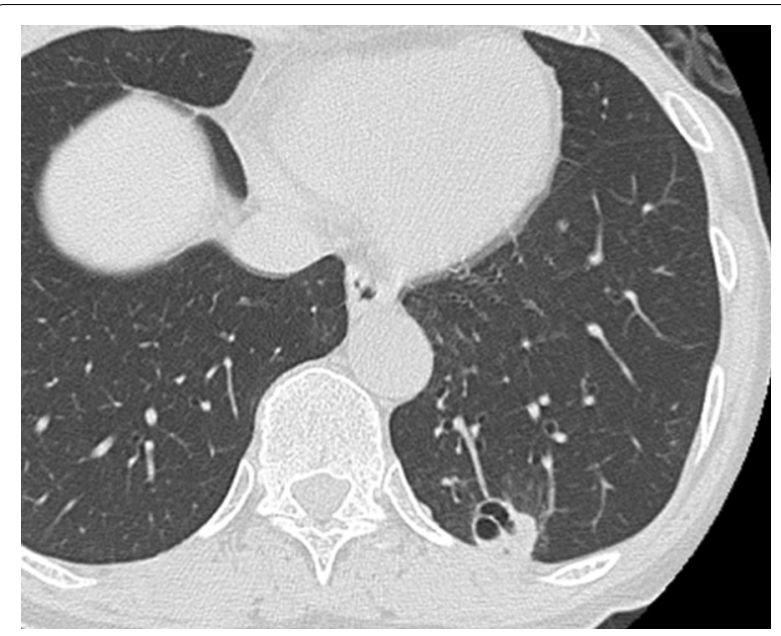

Fig. 2 Computed tomography scan of the chest. A computed tomography scan of the chest showing an irregularly shaped solitary nodule in the periphery of the left lower lobe. The nodule was in contact with the pleura, and bronchial dilatation was seen inside the nodule

radiograph on the day of hospitalization showed a leftsided pleural effusion (Fig. 1c). Given that there was no remarkable change in her general condition, videoassisted thoracoscopic surgery (VATS) was performed as planned. About $300 \mathrm{ml}$ of pale yellow transparent pleural effusion was found in the thoracic cavity and removed by suction. The parietal and visceral pleura near the nodule were slightly thickened with numerous scattered white small granules. (Fig. 3a, b). There was partial adhesion between the parietal and visceral pleura (Fig. 3c). Partial resection of the left lower lobe

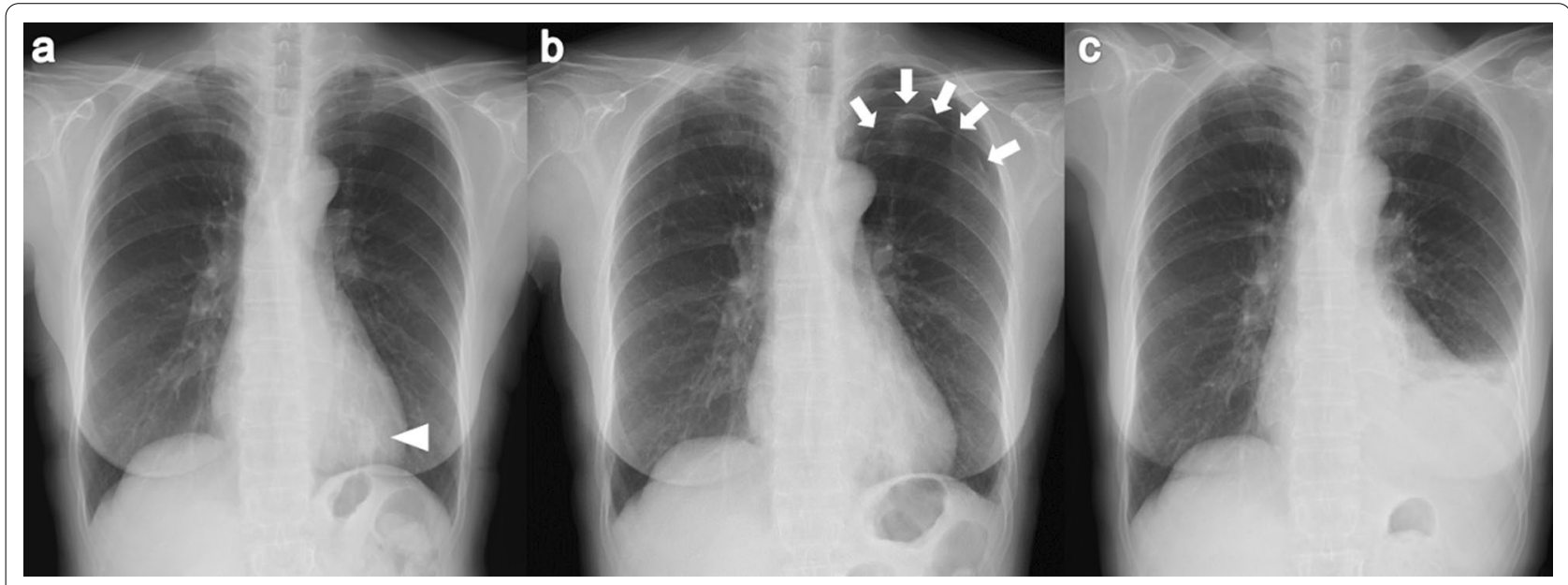

Fig. 1 Chest radiograph of the lung. a Chest radiograph obtained before performing bronchoscopy showing a solitary nodule in the left lower lung field (arrowhead). b Chest radiograph obtained immediately after bronchoscopy showing a left-sided pneumothorax (arrow). c Chest radiograph obtained on the day of hospitalization for surgery showing a left-sided pleural effusion. 


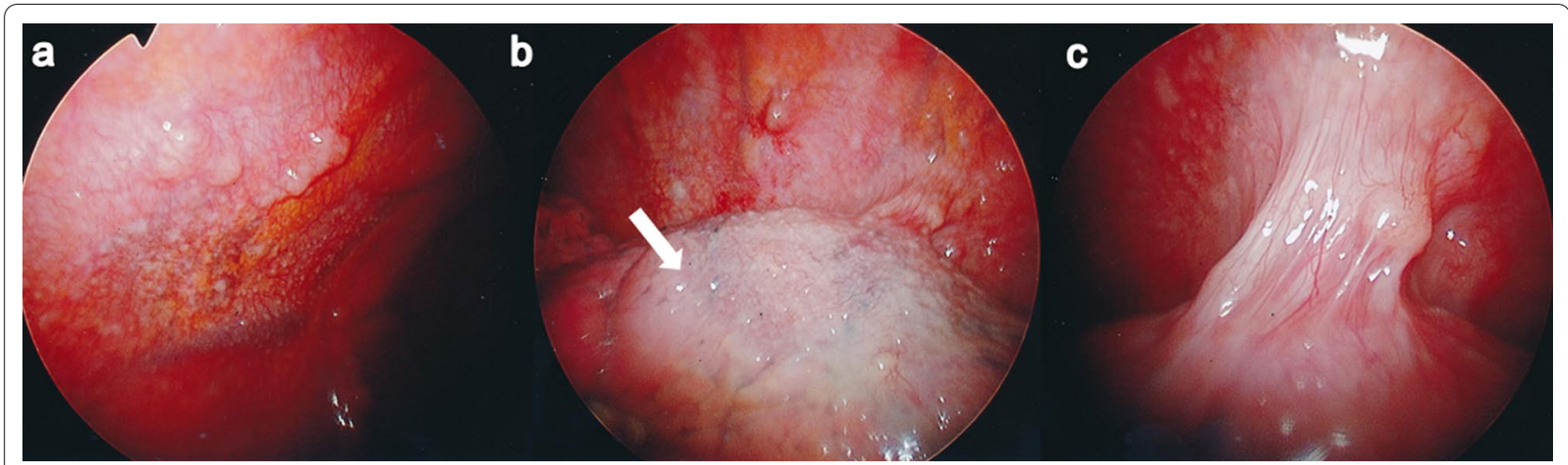

Fig. 3 Thoracoscopic images. a Parietal pleura and $\mathbf{b}$ visceral pleura (arrow) were slightly thickened with numerous scattered white small granules. c Partial adhesion between the parietal and visceral pleura

including the nodule and a parietal pleura biopsy were performed. Histologic examination of the resected left lower lobe and parietal pleura showed an epithelioid cell granuloma with caseous necrosis (Fig. 4a, c). There was no evidence of malignancy. Although tissue and pleural fluid cultures were negative, Ziehl-Neelsen stain-positive bacilli were observed in both lung and pleural tissues (Fig. 4b, d). Based on the histological findings, the patient was diagnosed with SPN and pleuritis caused by Mycobacterium avium infection. Combination chemotherapy of rifampin ( $450 \mathrm{mg} /$ day), ethambutol (500 mg/day), and clarithromycin $(800 \mathrm{mg} /$ day) for Mycobacterium avium infection was initiated after surgery. She had no complications, and there was no recurrence of pleural effusion 6 months after initiating postoperative chemotherapy.

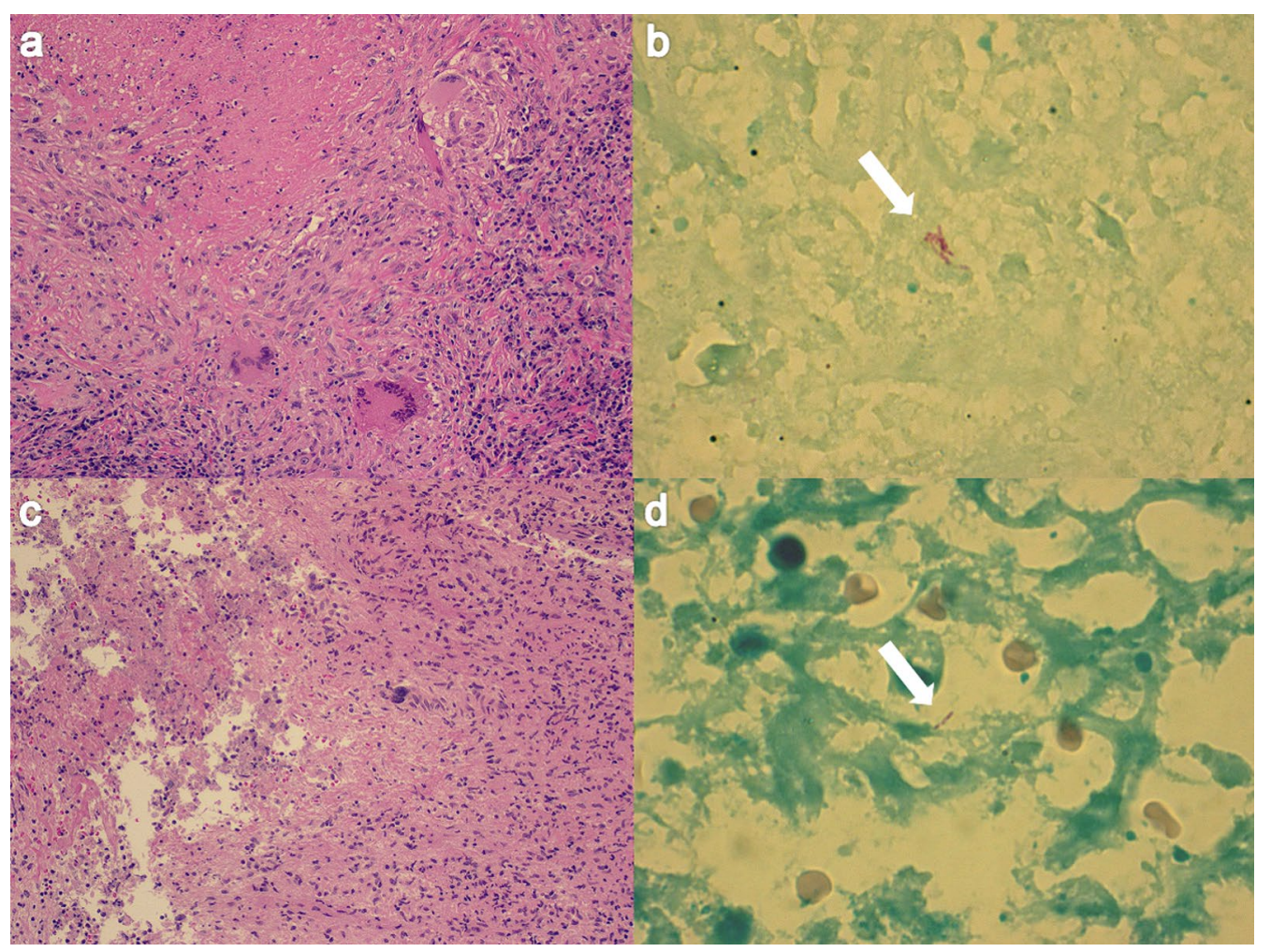

Fig. 4 Histologic findings for the lung $(\mathbf{a}, \mathbf{b})$ and parietal pleura $(\mathbf{c}, \mathbf{d})$. Photomicrographs showing an epithelioid cell granuloma with caseous necrosis in the resected lung (a) and the parietal pleura (c) (hematoxylin and eosin stain, $\times 10$ ). The photomicrographs show acid-fast bacilli in the resected lung $(\mathbf{b})$ and parietal pleura (d) (arrows, Ziehl-Neelsen stain, $\times 10$ ) 


\section{Discussion and conclusions}

Pleural effusion and pleuritis are uncommon manifestations of NTM infection [8-12]. Previous studies have reported that NTM pleuritis occurs in $1.2 \%$ of patients with NTM-PD [9], while MAC pleuritis occurs in 2.9$5.0 \%$ of patients with MAC-PD [9-11]. Although the radiologic findings of $\mathrm{MAC}-\mathrm{PD}$ are classified commonly into two types, that is, a fibrocavitary form and a nodular bronchiectatic form [5], there have been a few cases of MAC-SPN [6, 7]. MAC pleuritis tends to be seen more frequently in the fibrocavitary form than in the nodular bronchiectatic form $[8,9]$. However, pleuritis caused by MAC-SPN is extremely rare. To our knowledge, there is only one report of pleuritis attributable to MAC-SPN [13], and our case is the first report of MAC-SPN with pleuritis showing pleural effusion.

The mechanism via which pleuritis develops from NTM-PD has not been elucidated. However, it has been suggested that NTM may gain entry to the pleural cavity through a transient bacteremia or by direct spread from a subpleural lesion [14]. Moreover, two mechanisms have been proposed for direct spread. The first is direct infiltration of the infectious pulmonary lesion, and the second is leakage of NTM from the subpleural lesion into the pleural cavity through rupture of the pleura $[8,15]$.

It has been reported that secondary spontaneous pneumothorax (SSP) occurs in advanced stages of NTM-PD [16]. It has also been reported that SSP is a frequent complication of NTM pleuritis. In previous studies, pneumothorax was observed in 11 of 12,2 of 9 , and 5 of 11 cases of NTM pleuritis [8, 10, 17]. Hence, it has been suggested that pneumothorax is one of the causes of NTM pleuritis [8]. In our case, rapid development of pleural effusion after pneumothorax was observed. Furthermore, spontaneous pleuritis caused by MAC-SPN is extremely rare. Therefore, it is possible that pleural rupture arising from pneumothorax was the cause of the pleuritis.

However, unlike in the reported cases, the pneumothorax in our case was not secondary spontaneous but iatrogenic pneumothorax. Although SPNs can be caused by various disorders, including neoplasms, infection, inflammation, and vascular and congenital abnormalities [18], diagnosis of this disorder is often challenging. Clinicians perform invasive procedures, including bronchoscopic biopsies and image-guided transthoracic needle aspiration (TTNA), to make a pathologic diagnosis [19]. The incidence rates of pneumothorax diagnosed by bronchoscopic biopsy, CT-guided TTNA, and ultrasound-guided TTNA have been reported to be $0-5.1 \%$, $20.5 \%$, and $4.4 \%$, respectively $[20,21]$. A diagnosis of SPN involves a risk of pneumothorax.

Moreover, SPNs attributable to NTM (NTM-SPN) are often located immediately beneath the pleura and are in contact with the surface of the visceral pleura. Ose et al. reported that $85.7 \%$ of NTM-SPNs were subpleural lesion, and $55.6 \%$ were in contact with the pleura [22]. Therefore, leakage of NTM into the pleural cavity may occur easily when pneumothorax occurs in patients with NTM-SPN.

In addition, although surgical resection is considered curative in patients with MAC-SPN, the need for postoperative antibiotic treatment remains controversial. The guidelines state that antibiotic treatment is not usually required following resection in the absence of other features of MAC-PD [7, 23]. However, in patients with MAC-SPN who develop pneumothorax, leakage of MAC from the subpleural lesion into the pleural cavity may occur. Therefore, in such cases, it is necessary to carefully observe the pleura during surgery and consider antibiotic treatment following surgery if needed.

In conclusion, we have encountered a patient with MAC-SPN who developed pleuritis after pneumothorax subsequent to transbronchial biopsy. Although a causal relationship between MAC pleuritis and SSP has been suggested, iatrogenic pneumothorax can also be a cause of pleuritis attributable to NTM. Clinicians should watch carefully for the appearance of secondary pleuritis after transbronchial biopsy even in patients with localized disease such as NTM-SPN.

\section{Abbreviations \\ NTM: Nontuberculous mycobacteria; MAC: Mycobacterium avium complex; NTM-PD: NTM pulmonary disease; MAC-PD: MAC pulmonary disease; MAC- SPN: MAC-PD presenting as a solitary pulmonary nodule; CT: Computed tomography; VATS: Video-assisted thoracoscopic surgery; SSP: Secondary spontaneous pneumothorax; TTNA: Transthoracic needle aspiration; NTM-SPN: SPN caused by NTM.}

\section{Acknowledgements}

None.

\section{Authors' contributions}

SN managed the patient and reviewed the literature. SM, a pathologist, evaluated the pathological findings. All authors actively participated in the conception, case interpretation, and writing of this article. All authors read and approved the final manuscript.

Funding

None.

Availability of data and materials Not applicable.

\section{Declarations}

Ethics approval and consent to participate Not applicable

Consent for publication

Written informed consent was obtained from the patient for publication of this case report and any accompanying images. A copy of the written consent is available for review by the Editor-in-Chief of this journal. 


\section{Competing interests}

The authors declare that they have no competing interests.

\section{Author details}

${ }^{1}$ Respiratory Medicine, National Hospital Organization Tokyo Medical Center, 2-5-1, Higashigaoka, Meguro, Tokyo 152-8902, Japan. ${ }^{2}$ National Hospital Organization Tokyo Medical Center, Pathology, Japan.

Received: 27 May 2020 Accepted: 25 May 2021

Published online: 11 July 2021

\section{References}

1. Mirsaeidi M, Machado RF, Garcia JG, Schraufnagel DE. Nontuberculous mycobacterial disease mortality in the United States, 1999-2010: a population-based comparative study. PLoS ONE. 2014;9:e91879. https:// doi.org/10.1371/journal.pone.0091879.

2. Satta G, McHugh TD, Mountford J, Abubakar I, Lipman M. Managing pulmonary nontuberculous mycobacterial infection time for a patientcentered approach. Ann Am Thorac Soc. 2014;11:117-21. https://doi.org/ 10.1513/AnnalsATS.201308-2780T.

3. Morimoto K, Iwai K, Uchimura K, Okumura M, Yoshiyama T, Yoshimori K, et al. A steady increase in nontuberculous mycobacteriosis mortality and estimated prevalence in Japan. Ann Am Thorac Soc. 2014;11:1-8. https:// doi.org/10.1513/AnnalsATS.201303-0670C.

4. Namkoong H, Kurashima A, Morimoto K, Hoshino Y, Hasegawa N, Ato M, et al. Epidemiology of pulmonary nontuberculous mycobacterial disease, Japan (1). Emerg Infect Dis. 2016;22:1116-7. https://doi.org/10.3201/ eid2206.151086

5. Hayashi M, Takayanagi N, Kanauchi T, Miyahara Y, Yanagisawa T, Sugita Y. Prognostic factors of $634 \mathrm{HIV}$-negative patients with Mycobacterium avium complex lung disease. Am J Respir Crit Care Med. 2012;185:57583. https://doi.org/10.1164/rccm.201107-12030C.

6. Gribetz AR, Damsker B, Bottone EJ, Kirschner PA, Teirstein AS. Solitary pulmonary nodules due to nontuberculous mycobacterial infection. Am J Med. 1981:70:39-43.

7. Griffith DE, Aksamit T, Brown-Elliott BA, Catanzaro A, Daley C, Gordin F, et al. An official ATS/IDSA statement: diagnosis, treatment, and prevention of nontuberculous mycobacterial diseases. Am J Respir Crit Care Med. 2007;175:367-416. https://doi.org/10.1164/rccm.200604-571ST.

8. Naito M, Maekura T, Kurahara Y, Tahara M, Ikegami N, Kimura Y, et al. Clinical features of nontuberculous mycobacterial pleurisy: a review of 12 cases. Intern Med. 2018;57:13-6. https://doi.org/10.2169/internalme dicine.9119-17.

9. Park S, Jo KW, Lee SD, Kim WS, Shim TS. Clinical characteristics and treatment outcomes of pleural effusions in patients with nontuberculous mycobacterial disease. Respir Med. 2017;133:36-41. https://doi.org/10. 1016/j.rmed.2017.11.005.

10. Ichiki H, Ueda S, Watanabe A, Sato C, Abe M. Nontuberculous pulmonary mycobacteriosis complicated by pleuritis. Nihon Kokyuki Gakkai Zasshi. 2011;49:885-9.
11. Christensen EE, Dietz GW, Ahn CH, Chapman JS, Murry RC, Anderson J, et al. Pulmonary manifestations of Mycobacterium intracellularis. AJR Am J Roentgenol. 1979;133:59-66.

12. Shu CC, Lee LN, Wang JT, Chien YJ, Wang JY, Yu CJ. Taiwan Anti-Mycobacteria Investigation (TAMI) Group. Int J Tuberc Lung Dis. 2010;14:635-41.

13. Asakura T, Ishii M, Haraguchi M, Kamiyama I, Kohno M, Sakamaki H, et al. Dry pleurisy complicating solitary pulmonary nodules caused by Mycobacterium avium: a case report. J Med Case Rep. 2015;9:238. https://doi. org/10.1186/s13256-015-0723-4.

14. Gribetz AR, Damsker B, Marchevsky A, Bottone EJ. Nontuberculous mycobacteria in pleural fluid. Assessment of clinical significance. Chest. 1985:87:495-8.

15. Kotani K, Hirose $Y$, Endo S, Yamamoto H, Makihara S. Surgical treatment of atypical Mycobacterium intracellulare infection with chronic empyema: a case report. J Thorac Cardiovasc Surg. 2005;130:907-8. https://doi.org/10. 1016/j.jtcvs.2005.02.054

16. Ueyama M, Asakura T, Morimoto K, Namkoong H, Matsuda S, Osawa T, et al. Pneumothorax associated with nontuberculous mycobacteria: a retrospective study of 69 patients. Medicine (Baltimore). 2016;95:e4246. https://doi.org/10.1097/MD.0000000000004246.

17. Sado T, Nakamura Y, Kita H. Clinical analysis of nontuberculous mycobacterial infection complicated by pleurisy. Kekkaku. 2014;89:821-4.

18. Erasmus JJ, Connolly JE, MCAdams HP, Roggli VL. Solitary pulmonary nodules: Part I. Morphologic evaluation for differentiation of benign and malignant lesions. Radiographics. 2000;20:43-58.

19. Touman AA, Vitsas W, Koulouris NG, Stratakos GK. Gaining access to the periphery of the lung: bronchoscopic and transthoracic approaches. Ann Thorac Med. 2017;12:162-70. https://doi.org/10.4103/atm.ATM_416_16.

20. Steinfort DP, Khor YH, Manser RL, Irving LB. Radial probe endobronchial ultrasound for the diagnosis of peripheral lung cancer: systematic review and meta-analysis. Eur Respir J. 2011:37:902-10. https://doi.org/10.1183/ 09031936.00075310.

21. DiBardino DM, Yarmus LB, Semaan RW. Transthoracic needle biopsy of the lung. J Thorac Dis. 2015;7(Suppl 4):S304-16. https://doi.org/10.3978/j.issn. 2072-1439.2015.12.16.

22. Ose N, Maeda $H$, Takeuchi Y, Susaki Y, Kobori Y, Taniguchi S, et al. Solitary pulmonary nodules due to non-tuberculous mycobacteriosis among 28 resected cases. Int J Tuberc Lung Dis. 2016;20:1125-9. https://doi.org/10. 5588/ijtld.15.0819.

23. Haworth CS, Banks J, Capstick T, Fisher AJ, Gorsuch T, Laurenson IF, et al. British Thoracic Society guidelines for the management of non-tuberculous mycobacterial pulmonary disease (NTM-PD). Thorax. 2017:72(Supp 2):ii1-64. https://doi.org/10.1136/thoraxjnl-2017-210927.

\section{Publisher's Note}

Springer Nature remains neutral with regard to jurisdictional claims in published maps and institutional affiliations.

Ready to submit your research? Choose BMC and benefit from

- fast, convenient online submission

- thorough peer review by experienced researchers in your field

- rapid publication on acceptance

- support for research data, including large and complex data types

- gold Open Access which fosters wider collaboration and increased citations

- maximum visibility for your research: over 100M website views per year

At BMC, research is always in progress.

Learn more biomedcentral.com/submissions 